\title{
The Persian version of the revised dyadic adjustment scale (RDAS): a validation study in infertile patients
}

Saman Maroufizadeh ${ }^{1}$, Reza Omani-Samani ${ }^{2}$, Mostafa Hosseini ${ }^{3}$, Amir Almasi-Hashiani ${ }^{4}$, Mahdi Sepidarkish ${ }^{5}$ and Payam Amini ${ }^{6^{*}}$

\begin{abstract}
Background: Infertility can have a powerful impact on marital quality. The Revised Dyadic Adjustment Scale (RDAS) is a widely used measure of marital quality. This scale has not been validated in infertile patients. Therefore, this study aimed to evaluate the reliability and validity of the RDAS in a sample of infertile patients.

Methods: The sample of this methodological study consisted of 254 infertile patients referring to a referral infertility clinic in Tehran, Iran. A battery of questionnaires was administered to the participants, including a demographic/ fertility questionnaire, the RDAS, the Relationship Assessment Scale (RAS), the Kansas Marital Satisfaction Scale (KMSS), the Couples Satisfaction Index- 4 Item (CSI-4), the Hospital Anxiety and Depression Scale (HADS), and the Perceived Stress Scale-4 Item (PSS-4). Internal consistency of the scale was assessed with Cronbach's alpha, construct validity was investigated using confirmatory factor analysis (CFA), and convergent validity was examined by correlating the RDAS with RAS, KMSS, CSI-4, HADS, and PSS-4 instruments.

Results: The mean total RDAS score was $49.26 \pm 9.34$, and 100 patients (39.4\%) had marital distress based on the cut-off value of $<48$. The second-order three-factor model of the RDAS exhibited an excellent fit to the data, as indicated by $x^{2} / \mathrm{df}=2.26 ; \mathrm{CFI}=0.96 ; \mathrm{GFI}=0.91 ; \mathrm{NFI}=0.93 ; \mathrm{IFI}=0.96 ; \mathrm{RMSEA}=0.071$ and SRMR $=0.050$. The RDAS and its subscales revealed satisfactory internal consistency that ranged from 0.664 to 0.847 . Convergent validity was confirmed by strong correlations between RDAS scores and scores on the RAS, KMSS, and CSI-4. These correlations also tended to be larger than correlations with measures of HADS-anxiety, HADS-depression, and PSS-4. Among demographic/fertility variables, only infertility duration was found to be correlated to the RDAS.
\end{abstract}

Conclusion: The RDAS is a reliable and valid inventory for measuring marital quality in infertile patients. Further validation studies are needed to generalize the underlying structure of the scale in various populations.

Keywords: Revised dyadic adjustment scale, Marital quality, Reliability, Validity, Infertility

\section{Introduction}

The particular evaluation of one's relationship is generally referred to as relationship satisfaction, which is a crucial aspect of life satisfaction [1, 2]. Among several components in the context of relationship satisfaction, marital satisfaction is an essential element and the phenomenon of marriage and family system [3]. Distinct characteristics of marriage heavily influence the quality

\footnotetext{
* Correspondence: payam.amini87@gmail.com

${ }^{6}$ Department of Biostatistics and Epidemiology, School of Public Health,

Ahvaz Jundishapur University of Medical Sciences, Ahvaz, Iran

Full list of author information is available at the end of the article
}

of marriage, population requirements, sort of behavior towards the partner and personality attributes, attachment style, couples' families, forgiveness and sacrifice, religion, emotional intelligence, personal health, sexual relations, behaviors and communication patterns such as intimacy, gratitude, aggression and hostile, good selfesteem, truthfulness, and teamwork [4-7]. Different surveys have shown that marriage satisfaction is affiliated with physical and mental health, social and personal health, neuroticism, well-being, happiness, psychological problems, and quality of life $[6,8-12]$.

(C) The Author(s). 2020 Open Access This article is distributed under the terms of the Creative Commons Attribution 4.0 International License (http://creativecommons.org/licenses/by/4.0/), which permits unrestricted use, distribution, and 
Infertility is one of the main areas where marriage quality is heavily impacted. Infertility is a couple's failure to get pregnant even with regular, unprotected intercourse for at least 12 months [13].. It has been reported that the global prevalence of infertility is $8-12 \%$ of couples [14]. The assessment of marital satisfaction among the infertile patient population is challenging regarding multiple psychological and mental health issues like depression, stress, anxiousness, sexual problems, low standard of living, and poorer marital adjustment [1518].. Concerning the well-known effect of infertility on psychological factors and the hypothesis of a mutual association between infertility and mental health problems, the process wherein depression, stress and anxiety influence infertility seems to be a subject of discussion [14].. Previous surveys have shown that infertility impacts mental well-being, marriage relationships, sexual interactions, and life quality [17].

There are many self-reported instruments for evaluating marriage quality, such as Marital Adjustment Test (MAT), Kansas Marital Satisfaction Scale (KMSS), Dyadic Adjustment Scale (DAS) and its Revised Form (RDAS), Couples Satisfaction Index (CSI), Quality Marriage Index (QMI) and Relationship Assessment Scale (RAS) [19]. To the best of our knowledge, there were no disease-specific scales to assess the marital adjustment for couples with infertility. The 32-item DAS was first created by Spanier in 1976 to measure dyadic adjustment which is composed of dyadic consensus, dyadic satisfaction, dyadic cohesion, and affectional expression [20]. The benefit of DAS is the capacity to identify disputes in pair interactions, to use the dimensions individually and to assist find the most excellent therapeutic or preventive action [21]. Furthermore, there were many issues with the accuracy of distressed and non-distressed samples for at least two of the subscales [22]. Busby subsequently launched the updated edition of DAS in 1995, and scientists were prepared to use it with distressed and non-distressed couples [22]. The advantages of 14item RDAS are the enhancement of psychometric characteristics, its' shorter form in comparison to the DAS and includes three aspects, including dyadic consensus dyadic satisfaction and dyadic cohesion [22]. Even though the same length scale instruments are applicable as CSI-16, the RDAS is beneficial because of the possibility of investigating couple relationships more broadly [23]. Although the Persian version of RDAS has been validated among general population in Iran, it is important to evaluate this scale among infertile sample regarding their considerable marital conflicts [24].

Despite the relative strength of the RDAS compared to comparable instruments, it is not clear whether the RDAS is still precise to evaluate patients' marriage performance with infertility knowledge. The main aim of the present research was to examine the reliability and validity of RDAS in a sample of patients with infertility. In addition, a secondary aim was to examine the relationship between demographic/infertility variables and dyadic adjustment among this population.

\section{Methods \\ Participants and study design}

In this methodological study, infertile patients referring to infertility treatment clinic of Royan Institute, Tehran, Iran were invited to participate in the research project. We collected data in the evaluation phase of treatment using the convenience sampling method from February to May 2017.

The data were collected through the use of convenience sampling method from February to May 2017. The eligibility criteria for this study were as follows: (1) infertile couples; (2) legal married couples who are admitted to infertility clinic; (3) 18 years or older; (4) ability to read and write in Persian. Infertility is defined as "the failure to establish a clinical pregnancy after 12 months of regular, unprotected sexual intercourse or due to an impairment of a person's capacity to reproduce either as an individual or with his/her partner." [25]. The number of participants required for factor analysis was calculated using the rule of thumb suggested by Guilford [26] and Cattell [27]. They urged researchers to obtain samples of 200 (or 250) observations whenever possible. A total of 254 infertile patients agreed to take part and fill out the instruments altogether.

\section{Measures}

\section{Demographic and infertility information}

Demographic and infertility information of participants including age, sex, educational level, duration of infertility, cause of infertility, failure of previous treatment, and history of abortion were collected.

\section{Revised dyadic adjustment scale (RDAS)}

The RDAS is a short form of the original Dyadic Adjustment Scale that measures marital quality [22]. This scale is developed by Busby et al. among clinical and nonclinical couples in USA in 1995 [22]. The RDAS consists of 14 items that comprise three subscales: Consensus (item 1-6), Satisfaction (item 7-10), and Cohesion (item1114). All items are scored on a 6-point Likert scale ranging from 0 to 5 , except for Item 11 which is scored on a 5-point Likert scale ranging from 0 to 4 . Total scores can range from 0 to 69 , with higher scores indicating more marital quality.

\section{Relationship assessment scale (RAS)}

The RAS is a brief, 7-item self-administered inventory that measures relationship satisfaction [1]. 
Table 1 Demographic and fertility characteristics of the infertile patients $(n=254)$

\begin{tabular}{ll}
\hline & mean \pm SD or $n(\%)$ \\
\hline Age (years) & $32.09 \pm 6.55$ \\
Male & $113(44.5)$ \\
Female & $141(55.5)$ \\
Educational level & \\
Primary & $61(24.0)$ \\
Secondary & $101(39.8)$ \\
University & $92(36.2)$ \\
Duration of infertility (years) & $4.85 \pm 3.73$ \\
Cause of infertility & \\
Male factor & $91(35.8)$ \\
Female factor & $55(21.7)$ \\
Both & $49(19.3)$ \\
Unexplained & $59(23.2)$ \\
Failure of previous treatment & \\
No (First Treatment) & $128(50.4)$ \\
Yes & $126(49.6)$ \\
History of abortion & \\
No & $194(76.4)$ \\
Yes & $60(23.6)$ \\
\hline SD: Standard deviation &
\end{tabular}

SD: Standard deviation
This scale is developed by Hendrick in USA in 1988. All items are scored on a 5-point Likert scale ranging from 1 to 5 , total scores can range from 7 to 35, with higher scores indicating more relationship satisfaction. The Persian version of RAS has been shown to have sound psychometric properties in infertile patients [28].

\section{Kansas marital satisfaction scale (KMSS)}

The KMSS is an ultra-brief, 3-item, self-administered inventory that measures marital satisfaction [29]. This scale is developed by Schumm et al. among sample of married mothers in 1983 [29]. All items are scored on a 7 -point Likert scale ranging from 1 to 7 . Total scores can range from 3 to 21, with higher scores indicating more marital satisfaction. The Persian version of KMSS has been shown to have sound psychometric properties in infertile patients [30].

\section{The couples satisfaction index- 4 item (CSI-4)}

The CSI-4 is an ultra-brief self-administered inventory derived from the original 32 item CSI (CSI-32) that measures relationship satisfaction [31]. This scale is developed by Funk and Rogge among online sample of respondents in USA in 2007 [31]. The first item is scored on a 7-point Likert scale ranging from 0 to 6 , and the other three elements are scored on a 6-point Likert scale, ranging from 0 to 5 . Total scores can range from 0

Table 2 Descriptive statistics and internal consistency of the RDAS

\begin{tabular}{|c|c|c|c|c|c|c|c|c|c|c|}
\hline \multirow[t]{2}{*}{ Item } & \multirow[t]{2}{*}{ Mean } & \multirow[t]{2}{*}{ SD } & \multicolumn{4}{|c|}{ Corrected item-total correlation } & \multicolumn{4}{|c|}{ Alpha if item deleted } \\
\hline & & & Consensus & Satisfaction & Cohesion & RDAS & Consensus & Satisfaction & Cohesion & RDAS \\
\hline 1 & 4.04 & 1.11 & 0.292 & & & 0.263 & 0.829 & & & 0.850 \\
\hline 2 & 4.20 & 0.96 & 0.664 & & & 0.575 & 0.749 & & & 0.833 \\
\hline 3 & 3.97 & 1.03 & 0.672 & & & 0.551 & 0.744 & & & 0.834 \\
\hline 4 & 3.98 & 1.08 & 0.542 & & & 0.472 & 0.773 & & & 0.838 \\
\hline 5 & 3.94 & 1.09 & 0.635 & & & 0.606 & 0.751 & & & 0.831 \\
\hline 6 & 3.86 & 1.19 & 0.579 & & & 0.556 & 0.765 & & & 0.833 \\
\hline 7 & 4.30 & 1.05 & & 0.681 & & 0.547 & & 0.802 & & 0.834 \\
\hline 8 & 3.44 & 0.94 & & 0.663 & & 0.584 & & 0.810 & & 0.833 \\
\hline 9 & 4.39 & 0.99 & & 0.681 & & 0.590 & & 0.802 & & 0.832 \\
\hline 10 & 3.33 & 0.99 & & 0.695 & & 0.554 & & 0.795 & & 0.834 \\
\hline 11 & 2.17 & 0.99 & & & 0.367 & 0.368 & & & 0.650 & 0.844 \\
\hline 12 & 2.55 & 1.33 & & & 0.534 & 0.553 & & & 0.538 & 0.833 \\
\hline 13 & 2.14 & 1.60 & & & 0.562 & 0.441 & & & 0.507 & 0.844 \\
\hline 14 & 2.94 & 1.54 & & & 0.360 & 0.379 & & & 0.662 & 0.848 \\
\hline Consensus & 23.99 & 4.59 & & & & & & & & \\
\hline Satisfaction & 15.46 & 3.29 & & & & & & & & \\
\hline Cohesion & 9.81 & 3.91 & & & & & & & & \\
\hline RDAS & 49.26 & 9.34 & & & & & & & & \\
\hline Cronbach's a & & & & & & & 0.801 & 0.844 & 0.664 & 0.847 \\
\hline
\end{tabular}


Table 3 Correlations between the RDAS subscales

\begin{tabular}{lllll}
\hline & Consensus & Satisfaction & Cohesion & RDAS \\
\hline Consensus & 1 & & & \\
Satisfaction & 0.473 & 1 & & \\
Cohesion & 0.401 & 0.452 & 1 & \\
RDAS & 0.825 & 0.773 & 0.774 & 1 \\
\hline
\end{tabular}

All correlations were significant at 0.001 level

to 21 , with higher scores indicating more relationship satisfaction.

\section{Hospital anxiety and depression scale (HADS)}

The HADS is a commonly used self-administered inventory consisting of 14 items designed to measure both anxiety (HADS-A, seven items) and depression (HADS-D, seven items) [32]. This scale is developed by Zigmond and Snaith in 1983 for use in clinical and nonclinical samples [32]. All items are scored on a 4-point Likert scale ranging from 0 to 3. Both subscale scores can range from 0 to 21 , with higher scores indicating more anxiety and depression. The Persian version of HADS has been shown to have sound psychometric properties in infertile patients and widely used in this population $[16,33]$.

\section{Perceived stress Scale-4 item (PSS-4)}

The PSS-4 is an ultra-brief self-administered inventory derived from the original 14-item PSS (PSS-14) that measures perceived stress [34]. It introduced by Cohen and collogues in 1988 for situations requiring a very short scale or telephone interviews [34, 35]. All items are scored on a 5 -point Likert scale, ranging from 0 to 4 . Total scores can range from 0 to 16 , with higher scores indicating more perceived stress. The Persian version of PSS has been shown to have sound psychometric properties in infertile patients and adults with asthma [36, 37].

\section{Statistical analysis}

The confirmatory factor analysis (CFA), with the maximum likelihood estimation method, was performed to investigate the factor structure of the RDAS. Overall

Table 4 Correlations coefficients between RDAS scores and other measures of marital satisfaction, and measures of anxiety, depression and stress

\begin{tabular}{lllllll}
\hline & RAS & KMSS & CSI-4 & HADS-A & HADS-D & PSS-4 \\
\hline RDAS & 0.688 & 0.667 & 0.591 & -0.457 & -0.483 & -0.487 \\
Consensus & 0.521 & 0.447 & 0.504 & -0.327 & -0.361 & -0.380 \\
Satisfaction & 0.666 & 0.674 & 0.543 & -0.427 & -0.411 & -0.492 \\
Cohesion & 0.475 & 0.504 & 0.365 & -0.351 & -0.384 & -0.305 \\
\hline
\end{tabular}

All correlations were significant at 0.001 level

RDAS: Revised Dyadic Adjustment Scale; RAS: Relationship Assessment Scale; KMSS: Kansas Marital Satisfaction Scale; CSI-4: Couples Satisfaction Index- 4 Item (CSI-4); HADS: Hospital Anxiety and Depression Scale; PSS-4: Perceived Stress Scale-4 Item model fit was assessed using several goodness-of-fit indices including the chi-square/degree of freedom $\left(x^{2} / \mathrm{df}\right)$, the comparative fit index (CFI), the goodness of fit index (GFI); the incremental fit index (IFI); the normed fit index (NFI); the root mean square error of approximation (RMSEA), and the standardized root mean square residual (SRMR). Values of $\chi^{2} / \mathrm{df}<3, \mathrm{CFI}, \mathrm{GFI}, \mathrm{NFI}$, and IFI $>0.95$, and RMSEA and $S R M R<0.08$ indicate good fit to the data [38-41]. Cronbach's alpha was used to examine the internal consistency of the scale. The convergent validity of the scale was assessed by examining the relationship between RDAS scores and scores on the other measures of marital quality, HADS, and PSS-4. Additionally, to explore the relationship between RDAS scores and demographic/fertility variables, the Pearson correlation coefficient, independent t-test, and one-way ANOVA were used.

All data analyses were performed using SPSS for Windows, version 16.0 (SPSS Inc., Chicago, IL, USA), except for the CFA, which was conducted using LISREL 8.80 (Scientific Software International, Inc., Lincolnwood, IL, USA).

\section{Results}

\section{Participant characteristics}

The demographic and fertility characteristics of infertile patients are outlined in Table 1. The average age and infertility duration of the participants were 32.09 (SD = $6.55)$ and $4.85(\mathrm{SD}=3.73)$ years, respectively. Of the patients, $55.5 \%$ were female, $36.2 \%$ were universityeducated, $35.8 \%$ had male factor cause of infertility, $49.6 \%$ had a failure in previous infertility treatments.

\section{Descriptive statistics of the RDAS}

Descriptive statistics and reliability analysis of the RDAS are given in Table 2. The mean RDAS total score was $49.26 \pm 9.34$. Based on the cut-off value of $<48,100$ patients $(39.4 \%)$ had marital distress.

\section{Correlations between RDAS subscales}

Table 3 presents relationships among RDAS subscales. The findings indicate that the correlations between the RDAS subscales are statistically significant. These correlations demonstrate a link between the subscales, but not so strong that they would be taken as a single entity (thus justifying the existence of the subscales).

\section{Internal consistency of the RDAS}

Cronbach's alpha coefficients for assessing the internal consistency of the RDAS were as follows: RDAS total (14 items, $\alpha=0.847$ ), Consensus subscale (6 items, $\alpha=$ 0.801 ), Satisfaction subscale ( 4 items, $\alpha=0.844$ ), and Cohesion subscale $(4$ items, $\alpha=0.664)$. These values remained stable if one item was deleted (see Alpha if 


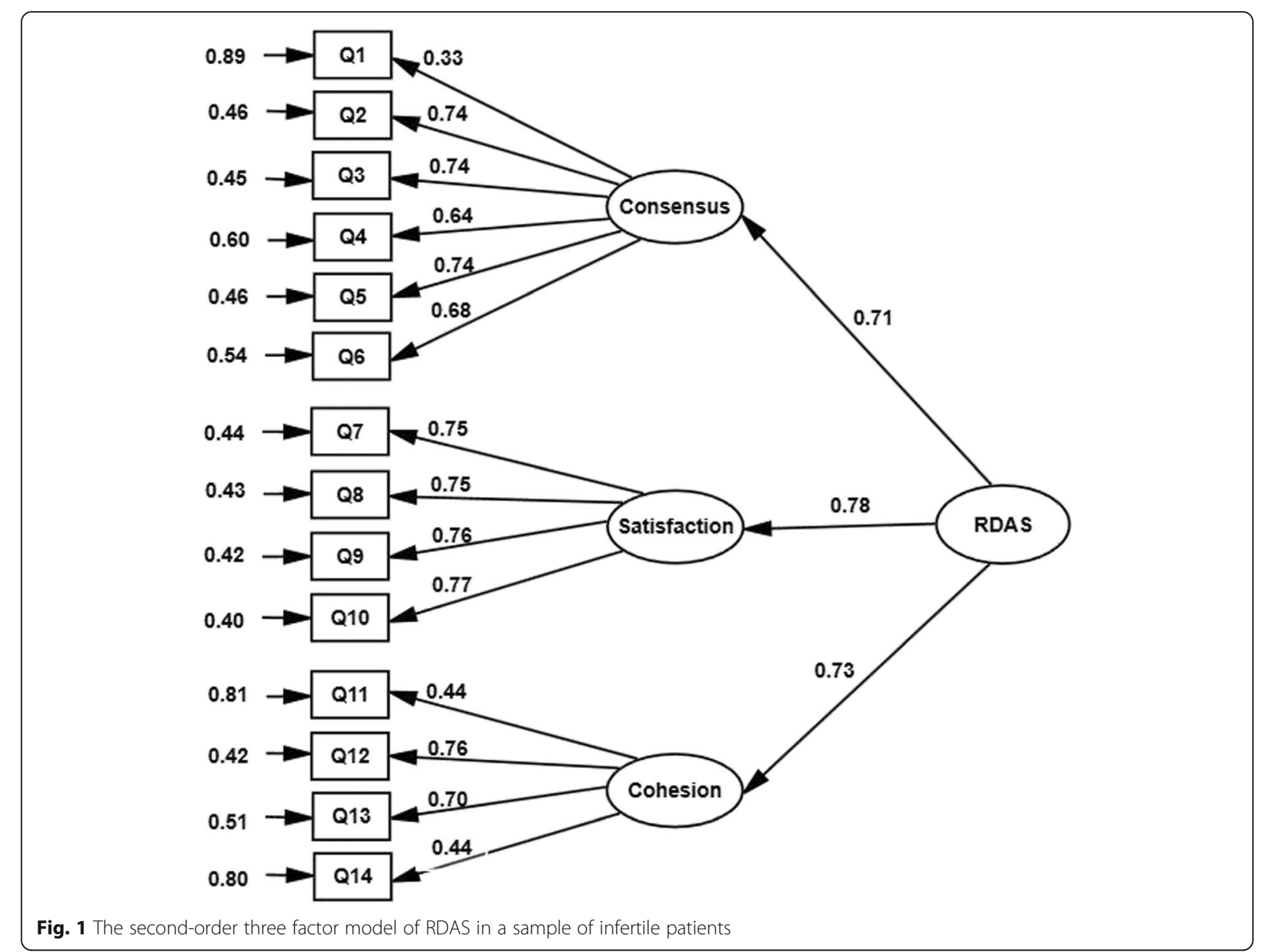

item removed values in Table 2). The corrected itemtotal correlations were between $0.263-0.606$.

\section{Convergent validity}

As anticipated, there were strong correlations between RDAS total scores and measures of RAS $(r=0.688)$, KMSS $(r=0.667)$, and CSI $4(r=0.591)$. The RDAS total scores were also negatively correlated with measures of HADS-A $(r=-0.457)$, HADS-D $(r=-0.483)$, and PSS-4 $(r=-0.487)$. Similar results were also obtained for RDAS subscales. An inspection of these correlation coefficients (see Table 4) indicates that RDAS scores correlate more highly with measures of marital satisfaction (i.e., RAS, KMSS, and CSI-4) than with measures of anxiety, depression, and perceived stress (i.e., HADS-A, HADS-D, and PSS-4).

\section{Confirmatory factor analysis}

To investigate the factor structure of the RDAS, the CFA was carried out. According to the goodness of fit indices, the fitness of the second-order three-factor model of RDAS was satisfactory $\left(\mathrm{X}^{2} / \mathrm{df}=2.26\right.$; $\mathrm{CFI}=0.96$;
$\mathrm{GFI}=0.91 ; \quad \mathrm{NFI}=0.93 ; \quad \mathrm{IFI}=0.96 ; \quad \mathrm{RMSEA}=0.071$ and SRMR $=0.050)$. As presented in Fig. 1, all standardized factor loadings were significant and in the expected direction, ranging from 0.33 to 0.77 .

\section{Relationship of the RDAS scores with demographic characteristics}

As shown in Table 5, a significant but low negative correlation was found between RDAS total scores and duration of infertility $(\mathrm{r}=-0.176, P=0.005)$. Patients who had a failure in previous treatment obtained lower RDAS scores compared to patients undergoing first treatment, but this difference was not statistically significant $(P=$ 0.056). Age, sex, educational level, cause of infertility, and history of abortion were not related to RDAS scores.

\section{Discussion}

This study examined the psychometric characteristics of the RDAS in a sample of infertile patients in Iran. In this study the prevalence of marital distress was $39.4 \%$, which is higher than what was reported in primary care patients in Nigeria (30.0\%) [42], in couples facing breast 
Table 5 Relationship of RDAS total scores with demographic/ fertility variables in infertile patients

\begin{tabular}{lll}
\hline & mean \pm SD or $r$ & $\mathrm{P}$ \\
\hline Age (years) & -0.058 & 0.354 \\
Duration of infertility (years) & -0.176 & 0.005 \\
Sex & & $0.756^{\dagger}$ \\
Male & $49.46 \pm 9.88$ & \\
Female & $49.09 \pm 8.92$ & $0.565^{\ddagger}$ \\
Educational level & & \\
Primary & $48.21 \pm 9.35$ & \\
Secondary & $49.83 \pm 9.56$ & \\
$\quad$ University & $49.32 \pm 9.14$ & \\
Cause of infertility & & \\
Male factor & $47.53 \pm 9.99$ & \\
Female factor & $51.71 \pm 8.73$ & \\
Both & $50.20 \pm 9.04$ & $0.056^{\dagger}$ \\
Unexplained & $48.85 \pm 8.73$ & \\
Failure of previous treatment & & $0.260^{\dagger}$ \\
No (First treatment) & $50.37 \pm 9.22$ & \\
Yes & $48.13 \pm 9.37$ & \\
History of abortion & $49.62 \pm 9.12$ & \\
No & $48.07 \pm 10.01$ & \\
Yes & & \\
\hline
\end{tabular}

SD: Standard deviation; r: Correlation Coefficients

'Independent $\mathrm{t}$ test

‡One-way ANOVA

cancer $(27.0 \%)$ [43], and in prostate cancer patients and their partner (16\%) [44]. A comprehensive approach, including psychosocial interventions and support, is required to improve the marital quality in these patients.

The RDAS and its subscales demonstrated satisfactory internal consistency, and alpha value did not increase after deleting any one of the items. All corrected item-total correlations were also within an acceptable range, indicating good internal consistency. These findings are consistent with what was reported in previous studies [22, 45, 46].

The second-order three-factor model demonstrated good fit indices in this study, which is consistent with the original research by Busby et al. [22] and in a sample of married adults in Romania [45]. Unfortunately, the literature in which the factor structure of the RDAS has been studied is limited.

Convergent validity of the scale was confirmed by strong correlations between RDAS scores and scores on the RAS, KMSS, and CSI-4 instruments. These findings are following the previous research, which found that the RDAS scores were correlated to other measures of marital quality and satisfaction [24, 47, 48]. These correlations also tended to be larger than correlations with measures of anxiety, depression, and stress.
Among demographic and fertility factors, only infertility duration was significantly related to RDAS scores, as infertile patients with long infertility duration had lower marital quality. This result is consistent with previous research $[28,30]$. Besides, similar results have been found in other research on measures of quality of life [49], anxiety, and depression [50-53]. Consistent with a study by Turliuc and Muraru [45], there was no significant difference between males and females in RDAS scores.

There are several limitations to the study that should be considered. First, the present study was conducted only in one center and thus may not be generalizable. Second, the cross-sectional nature of the study design limits our ability to make causal inferences between RDAS scores and demographic/fertility information. Third, due to practical reasons, the test-retest reliability of the RDAS was not assessed in this study. Furth, although the cut-off point is available for the English version, further research is required to determine the cutoff point for the Iranian population.

\section{Conclusions}

In sum, the RDAS is a reliable and valid inventory for measuring marital quality in infertile patients. Furthermore, the CFA finding provides additional support for the three-factor structure of the RDAS and use of the subscales as distinct variables. Nevertheless, future studies should examine the psychometric properties of RDAS in diverse populations, particularly its test-retest reliability.

\section{Abbreviations}

CFA: Confirmatory Factor Analysis; CFI: Comparative Fit Index; CSI-4: Couples Satisfaction Index- 4 Item; GFI: Goodness of Fit Index; HADS: Hospital Anxiety and Depression Scale; IFI: Incremental Fit Index; KMSS: Kansas Marital Satisfaction Scale; NFI: Normed Fit Index; PSS-4: Perceived Stress Scale- 4 Item; RAS: Relationship Assessment Scale; RDAS: Revised Dyadic Adjustment Scale; RMSEA: Root Mean Square Error of Approximation; SD: Standard Deviation; SRMR: Standardized Root Mean Square Residual

\section{Acknowledgments}

The authors would like to thank all infertile patients who participated in this research project and to the Royan Institute, Tehran, Iran for cooperation in data acquisition.

\section{Author contributions}

SM and PA: Conception and study design; Analysis and interpretation of the data; Drafting of the article. ROS and MH: Conception and design; Collection and assembly of data; Drafting of the article. AAH and MS: Conception and study design; Interpretation of the data; Drafting of the article. All authors approved the final version of the article for submission.

\section{Funding}

This research received no specific grant from any agency in the public, commercial, or not-for-profit sector.

Availability of data and materials

The datasets used and/or analyzed during the current study are available from the corresponding author on reasonable request. 


\section{Ethics approval and consent to participate}

The Ethics Committee of Royan Institute, Tehran, Iran, approved this study (Registration Number: IR.ACECR.ROYAN.REC.1397.47). The patients were informed about the aim of the study and were assured of confidentiality, and a verbal informed consent was obtained from all participants before data collection.

\section{Consent for publication}

Not applicable.

\section{Competing interests}

The authors declare that they have no competing interests.

\section{Author details}

${ }^{1}$ School of Nursing and Midwifery, Guilan University of Medical Sciences, Rasht, Iran. ${ }^{2}$ Department of Medical Ethics and Law, Reproductive Biomedicine Research Center, Royan Institute for Reproductive Biomedicine, ACECR, Tehran, Iran. ${ }^{3}$ Department of Epidemiology and Biostatistics, School of Public Health, Tehran University of Medical Sciences, Tehran, Iran. ${ }^{4}$ Department of Epidemiology, School of Health, Arak University of Medical Sciences, Arak, Iran. ${ }^{5}$ Department of Biostatistics and Epidemiology, Babol University of Medical Sciences, Babol, Iran. ${ }^{6}$ Department of Biostatistics and Epidemiology, School of Public Health, Ahvaz Jundishapur University of Medical Sciences, Ahvaz, Iran.

\section{Received: 22 June 2019 Accepted: 19 January 2020}

\section{Published online: 29 January 2020}

\section{References}

1. Hendrick SS. A generic measure of relationship satisfaction. J Marriage Fam. 1988;50(1):93-8.

2. Falconier MK, Jackson JB, Hilpert P, Bodenmann G. Dyadic coping and relationship satisfaction: a meta-analysis. Clin Psychol Rev. 2015;42:28-46.

3. Pedro MF, Ribeiro T, Shelton KH. Romantic attachment and family functioning: the mediating role of marital satisfaction. J Child Fam Stud. 2015;24(11):3482-95.

4. Fincham FD, Bradbury TN. The assessment of marital quality: a reevaluation. J Marriage Fam. 1987:797-809.

5. Slatcher RB. Marital functioning and physical health: implications for social and personality psychology. Soc Personal Psychol Compass. 2010; 4(7):455-69.

6. Carr D, Freedman VA, Cornman JC, Schwarz N. Happy marriage, happy life? Marital quality and subjective well-being in later life. J Marriage Fam. 2014; 76(5):930-48.

7. Tavakol Z, Nikbakht Nasrabadi A, Behboodi Moghadam Z, Salehiniya H, Rezaei E. A review of the factors associated with marital satisfaction. Galen Med J. 2017:6(3):197-207.

8. Heru A. Improving marital quality in women with medical illness: integration of evidence-based programs into clinical practice. J Psychiatr Pract. 2010;16(5):297-305

9. Javanmard GH, Garegozlo RM. The study of relationship between marital satisfaction and personality characteristics in Iranian families. Procedia Soc Behav Sci. 2013;84:396-9.

10. Hardie $\mathrm{JH}$, Lucas A. Economic factors and relationship quality among young couples: comparing cohabitation and marriage. J Marriage Fam. 2010;72(5): 1141-54.

11. Harper A, Dyches TT, Harper J, Roper SO, South M. Respite care, marital quality, and stress in parents of children with autism spectrum disorders. J Autism Dev Disord. 2013;43(11):2604-16.

12. Liu H, Waite L. Bad marriage, broken heart? Age and gender differences in the link between marital quality and cardiovascular risks among older adults. J Health Soc Behav. 2014;55(4):403-23.

13. Inhorn M, Patrizio P. Infertility around the globe: new thinking on gender, reproductive technologies and global movements in the 21 st century. Hum Reprod Update. 2002;21(4):411-26.

14. Doyle M, Carballedo A. Infertility and mental health. Adv Psychiatr Treat. 2014;20(5):297-303.

15. Maroufizadeh S, Ghaheri A, Amini P, Samani RO. Psychometric properties of the fertility quality of life instrument in infertile Iranian women. Int J Fertil Steril. 2017;10(4):371-9.
16. Omani Samani R, Maroufizadeh S, Navid B, Amini P. Locus of control, anxiety, and depression in infertile patients. Psychol Health Med. 2017;22(1):44-50.

17. Luk BH-K, Loke AY. The impact of infertility on the psychological well-being, marital relationships, sexual relationships, and quality of life of couples: a systematic review. J Sex Marital Ther. 2015;41(6):610-25.

18. Gana K, Jakubowska S. Relationship between infertility-related stress and emotional distress and marital satisfaction. J Health Psychol. 2016;21(6):1043-54.

19. Reynolds J, Houlston C, Coleman L. Understanding relationship quality: Oneplus one; 2014.

20. Spanier GB. Measuring dyadic adjustment: new scales for assessing the quality of marriage and similar dyads. J Marriage Fam. 1976:15-28.

21. Montesino MLC, Gómez JLG, Fernández MEP, Rodríguez JMA. Psychometric properties of the dyadic adjustment scale (DAS) in a community sample of couples. Psicothema. 2013;25(4):536-41.

22. Busby DM, Christensen C, Crane DR, Larson JH. A revision of the dyadic adjustment scale for use with distressed and nondistressed couples: construct hierarchy and multidimensional scales. J Marital Fam Ther. 1995; 21(3):289-308

23. Anderson SR, Tambling RB, Huff SC, Heafner J, Johnson LN, Ketring SA. The development of a reliable change index and cutoff for the revised dyadic adjustment scale. J Marital Fam Ther. 2014;40(4):525-34.

24. Isanezhad O, Ahmadi S-A, Bahrami F, Baghban-Cichani I, Farajzadegan Z, Etemadi $\mathrm{O}$. Factor structure and reliability of the revised dyadic adjustment scale (RDAS) in Iranian population. Iran J Psychiatry Behav Sci. 2012;6(2):55-61.

25. Zegers-Hochschild F, Adamson G, Dyer S, Racowsky C, de Mouzon J, Sokol R, Rienzi L, Sunde A, Schmidt L, Cooke I, et al. The international glossary on infertility and fertility care, 2017. Fertil Steril. 2017;108(3):393-406.

26. Guilford JP. Psychometric methods. New York: McGraw Hill; 1954.

27. Cattell R. Use of factor analysis in behavioral and life sciences. New York: Plenum Press; 1978

28. Maroufizadeh S, Omani-Samani R, Almasi-Hashiani A, Navid B, Sobati B, Amini $P$. The relationship assessment scale (RAS) in infertile patients: a reliability and validity study. Middle East Fertil Soc J. 2018;23(4):471-5.

29. Schumm WR, Nichols C, Schectman K, Grigsby CC. Characteristics of responses to the Kansas marital satisfaction scale by a sample of 84 married mothers. Psychol Rep. 1983;53(2):567-72.

30. Omani-Samani R, Maroufizadeh S, Ghaheri A, Amini P, Navid B. Reliability and validity of the Kansas marital satisfaction scale (KMSS) in infertile people. Middle East Fertil Soc J. 2017;23(2):154-7.

31. Funk $J$, Rogge RD. Testing the ruler with item response theory: increasing precision of measurement for relationship satisfaction with the couples satisfaction index. J Fam Psychol. 2007;21(4):572-83.

32. Zigmond AS, Snaith RP. The hospital anxiety and depression scale. Acta Psychiatr Scand. 1983;67(6):361-70.

33. Amini $P$, Maroufizadeh $S$, Omani Samani R. Evaluating the factor structure, item analyses, and internal consistency of hospital anxiety and depression scale in Iranian infertile patients. Int J Reprod Biomed (Yazd). 2017;15(5):287-96.

34. Cohen $S$, Kamarck T, Mermelstein R. A global measure of perceived stress. J Health Soc Behav. 1983;24(4):385-96.

35. Lee $\mathrm{E}-\mathrm{H}$. Review of the psychometric evidence of the perceived stress scale. Asian Nurs Res (Korean Soc Nurs Sci). 2012;6(4):121-7.

36. Maroufizadeh S, Zareiyan A, Sigari N. Reliability and validity of Persian version of perceived stress scale (PSS-10) in adults with asthma. Arch Iran Med. 2014;17(5):361-5.

37. Maroufizadeh S, Foroudifard F, Navid B, Ezabadi Z, Sobati B, Omani-Samani R. The perceived stress scale (PSS-10) in women experiencing infertility: a reliability and validity study. Middle East Fertil Soc J. 2018;23(4):456-9.

38. Bentler PM. Comparative fit indexes in structural models. Psychol Bull. 1990; 107(2):238-46.

39. Byrne BM. Structural equation modeling with EQS and EQS/windows: basic concepts, applications, and programming. Thousand Oaks: Sage Publications; 1994.

40. McDonald RP, Ho M-HR. Principles and practice in reporting structural equation analyses. Psychol Methods. 2002;7(1):64-82.

41. Kline RB. Principles and practice of structural equation modeling. New York: Guilford Publications; 2015.

42. Nwakanma NC, Ofoedu JN. Depressive symptoms and marital adjustment among primary care patients with erectile dysfunction in Umuahia, Nigeria. S Afr J Psychiatr. 2016;22(1):979. 
43. Kraemer LM, Stanton AL, Meyerowitz BE, Rowland JH, Ganz PA. A longitudinal examination of couples' coping strategies as predictors of adjustment to breast cancer. J Fam Psychol. 2011;25(6):963.

44. Chambers SK, Schover L, Nielsen L, Halford K, Clutton S, Gardiner RA, Dunn J, Occhipinti S. Couple distress after localised prostate cancer. Support Care Cancer. 2013;21(11):2967-76.

45. Turliuc MN, Muraru AA. Psychometric properties of the revised dyadic adjustment scale on a sample of married adults. J Psychol Educ Res. 2013; 21(1):49-76

46. Hollist CS, Falceto OG, Ferreira LM, Miller RB, Springer PR, Fernandes CL, Nunes NA. Portuguese translation and validation of the revised dyadic adjustment scale. J Marital Fam Ther. 2012;38(s1):348-58.

47. Hunsley J, Pinsent C, Lefebvre M, James-Tanner S, Vito D. Construct validity of the short forms of the dyadic adjustment scale. Fam Relat. 1995:231-7.

48. Crane DR, Middleton KC, Bean RA. Establishing criterion scores for the Kansas marital satisfaction scale and the revised dyadic adjustment scale. Am J Fam Ther. 2000;28(1):53-60.

49. Karabulut A, Özkan S, Oğuz N. Predictors of fertility quality of life (FertiQoL) in infertile women: analysis of confounding factors. Eur J Obstet Gynecol Reprod Biol. 2013;170(1):193-7.

50. Maroufizadeh S, Ghaheri A, Almasi-Hashiani A, Mohammadi M, Navid B, Ezabadi Z, Omani Samani R. The prevalence of anxiety and depression among people with infertility referring to Royan Institute in Tehran, Iran: a crosssectional questionnaire study. Middle East Fertil Soc J. 2017;23(2):103-6.

51. Ramezanzadeh F, Aghssa MM, Abedinia N, Zayeri F, Khanafshar N, Shariat M, Jafarabadi M. A survey of relationship between anxiety, depression and duration of infertility. BMC Womens Health. 2004;4(1):9.

52. Omani-Samani R, Maroufizadeh S, Almasi-Hashiani A, Amini P. Prevalence of depression and its determinant factors among infertile patients in Iran based on the PHQ-9. Middle East Fertil Soc J. 2018;23(4):460-3.

53. Omani-Samani R, Ghaheri A, Navid B, Sepidarkish M, Maroufizadeh S. Prevalence of generalized anxiety disorder and its related factors among infertile patients in Iran: a cross-sectional study. Health Qual Life Outcomes. 2018;16(1):129

\section{Publisher's Note}

Springer Nature remains neutral with regard to jurisdictional claims in published maps and institutional affiliations.

Ready to submit your research? Choose BMC and benefit from:

- fast, convenient online submission

- thorough peer review by experienced researchers in your field

- rapid publication on acceptance

- support for research data, including large and complex data types

- gold Open Access which fosters wider collaboration and increased citations

- maximum visibility for your research: over $100 \mathrm{M}$ website views per year

At BMC, research is always in progress.

Learn more biomedcentral.com/submissions 